\title{
Research on Identification of Chinese Kindergarten Qualification Examination
}

\author{
Huilan Yue, Yunyan Liu \\ Southwest University, Chongqing, China \\ Email:yuehuilan21st@126.com
}

Received 14 July 2014; revised 30 August 2014; accepted 15 September 2014

Copyright $@ 2014$ by authors and Scientific Research Publishing Inc.

This work is licensed under the Creative Commons Attribution International License (CC BY). http://creativecommons.org/licenses/by/4.0/

(c) (i) Open Access

\section{Abstract}

The research in the thesis is based on the background of reform of Chinese kindergarten teacher qualification examination system, and is conducted as to the identification of new Chinese kindergarten teacher qualification examination by qualified pre-school teachers unit in Zhejiang Province. The research finds that: 1) The degree of identification of teacher qualification examination reform this time by cultivation organization is high on the whole. 2) The results of identification of kindergarten teacher qualification examination system by pre-education qualified teacher cultivation unit in all dimensions are: the average grades of organization form is the highest, followed by average grades of evaluation mode, and the rest dimensions are: timeliness, examination objects, examination contents, value and recognition of qualification. 3) There is no obvious difference in identification of kindergarten teacher qualification examination system by different types of qualified teacher cultivation units.

\section{Keywords}

Kindergarten Teacher Qualification System, Teacher Qualification Examination System, Kindergarten Teacher Cultivation Unit

\section{Introduction}

With the further progress of worldwide education reform, the quality of teachers has become the focus of the world, which prompted the development of Professional teaching standard. On the other hand, the educators have been making tireless efforts to make teaching a profession, which makes the birth of professional teaching standard become a necessity. Under this background, many countries come to take professional teaching standard as an important means to improve the quality of teachers and promote teaching as a profession. Teacher qualification system is one of them. 
The establishment of teacher certification system is the important process of teacher professionalization [1]. Teacher qualification system refers to a compulsory regulation made by the country as to conditions and identitys which should be owned by people working on teaching profession, and education and teaching activities, which is the legal occupational license of teacher executed by the country. It is the basic national requirements as to staff specially working on education and teaching, as well as legal premise of citizens for obtaining posts of teachers. The new Chinese teacher qualification system has been put into trail implementation since 2011 and this reform of system broke off the convention that normal university students can obtain teacher certification without participating in teacher qualification examination, and explicitly stipulated that all examiners can obtain teacher certification through passing examination.

System identification is a sense belonging generated based on people's affirmation as to special system, which is a high degree of trust and affirmation generated from heart of public. The continuation of establishment and its success of new teacher qualification system are fundamentally based on people's identification under this system. Only by forming public identification of system can the public trust of system be formed, for efficient transformation to be the self conscious measure value and code of conduct. However, once there is no public identification of the system, the system will lose its authority, and then the system arrangement will become an alien power.

In order to verify whether the reform of teacher qualification system has impacted current formal kindergarten teacher cultivation unit (cultivation unit is explicitly stipulated as pre-school education), and whether the system has gained the identification of normal university cultivation unit, the research is conducted. Because that there is regulation from Zhejiang Province that people with educational background below the level junior college can not participate in teacher qualification examination. As a result, in this research, the kindergarten teacher cultivation unit refers to unit cultivating undergraduates and junior college students.

\section{Material and Methods}

This study used two surveys. And the first one is the pre investigation; the second one is the formal investigation. According to the analysis of initial questionnaire item and reliability of the pre investigation, the study got the formal questionnaire. Analyzing all the data with statistics software SPSS, the study provides the following findings.

\subsection{Participants}

Extract randomly respectively 11 main relative principles (professional principles, professional forgoers, college directors and so on) cultivated by undergraduate education and junior college education majoring in pre-school education in Zhejiang Province. The total number is 22 (Table 1). In this survey, 22 questionnaires are issued with 20 returning, and the effective rate is $90.9 \%$.

\subsection{Research Instrument}

By referring to related document literature, the author will compile questionnaire from seven dimensions of organization form, examination mode, examination contents, examination objects, qualification recognition, timeliness of qualification and assessment efficiency.

\subsection{Procedure}

The formulation of instrument goes through two stages. At first, compile initial questionnaire, and then evaluate the science of questionnaire by related personnel, and the formal questionnaire is defined after rectification.

\section{Results and Discussions}

1) Testing of validity and reliability: the degree of validity and reliability of data is high.

This research first makes testing of validity and reliability as to data according to SPSS's testing of validity and reliability. Seen from Table 2, Cronbach's alpha $>0.8$, which indicates that the data is effective and supports the successive data analysis.

2) Analysis on overall situation of identification: the overall degree of identification is high.

The questionnaire is with a 5-point system, and 1 represents: disagree completely; 2 represents: disagree; 3 
represents: the uncertainty; 4 represents: agree; 5 represents: agree completely. Known from described statistic results (Table 3), the overall degree of identification of kindergarten teacher qualification examination by kindergarten teacher cultivation unit is pretty high in each dimension. According to degree of identification, the dimensions are listed as organization form, timeliness of examination mode, examination objects, examination contents, value and qualification recognition.

Among these dimensions, the grades of organization form and examination mode are highest, which indicates that teacher cultivation units are satisfied with two-time arrangement of kindergarten teacher qualification examinations in spring and autumn, as well as written examination and interview questions. Seen from analysis of standard deviation, the standard deviation of examination object is smallest, and the average grades of examination objects are high, which indicates that each cultivation unit has high degree of sense of identity as to the regulation that normal university students and non normal university students should participate in the examination.

Table 1. The demographic information of participants.

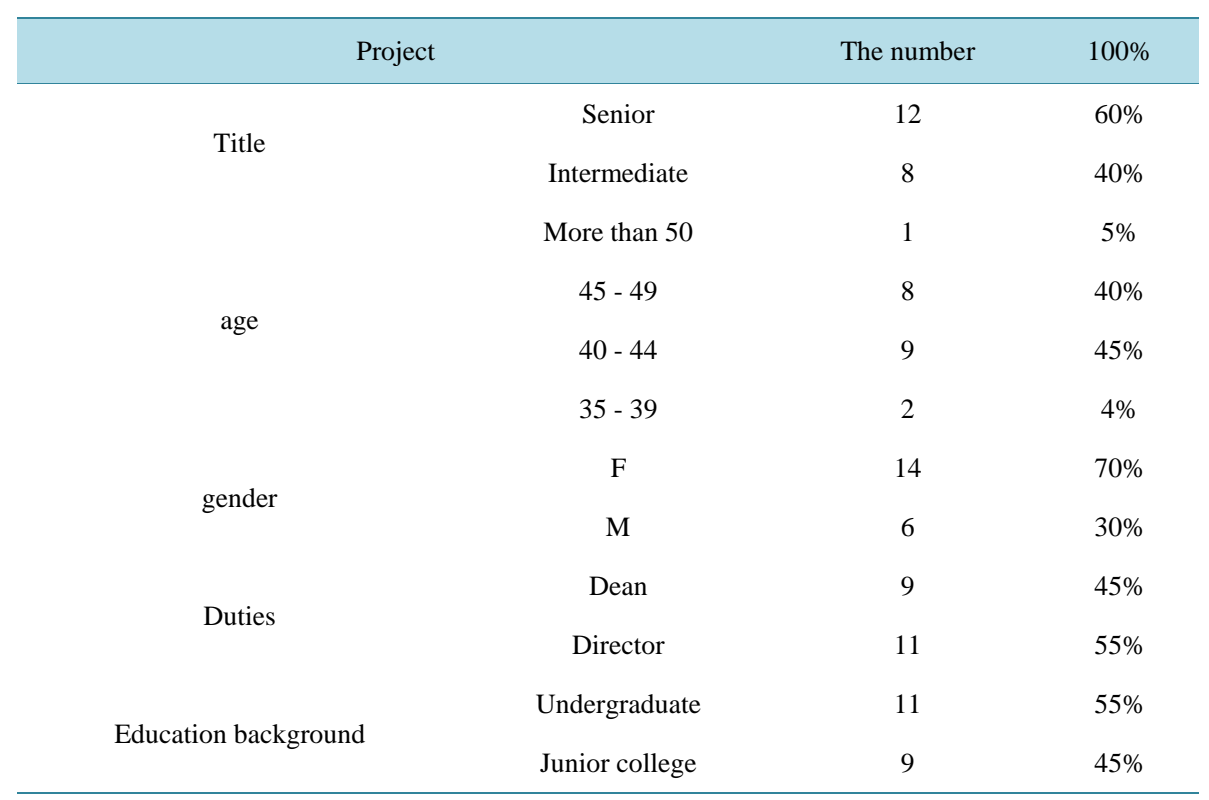

Table 2. Testing of validity and reliability.

\begin{tabular}{cc}
\multicolumn{2}{c}{ Reliability statistics } \\
\hline Cronbach's alpha & N of items \\
0.843 & 16 \\
\hline
\end{tabular}

Table 3. Description of overall situation of identification.

\begin{tabular}{ccc}
\hline Identification dimension & M & SD \\
\hline Organization form & 4.4667 & 0.55567 \\
Examination objects & 4.3 & 0.49441 \\
Qualification recognition & 3.9 & 1.25237 \\
Timeliness of qualification & 4.35 & 1.13671 \\
Examination mode & 4.4167 & 0.63867 \\
Examination contents & 4.3 & 0.55039 \\
Examination efficiency & 4.15 & 0.60914 \\
\hline
\end{tabular}


In China before 2011, every normal student can get the teacher's qualification certificate, and citizens who without the records of formal schooling for teachers' qualifications must pass the national teachers' qualification examinations. And only if have studied education psychology and pedagogies, they can enter themselves for the examination, admitted to the teacher qualification certificate. With the popularization of higher education in China, this system has become an obstacle to the teacher professional development system. Therefore, all walks of life are calling for reform of teacher qualification system. Before the study, many researchers think the pre-school teachers cultivation units should be the biggest challengers of new teacher system, but this is not the case.

3) There is no difference among different types of kindergarten teachers cultivation units.

In this table, 1 representatives of junior college, 2 representatives of the undergraduate. Known from results of independent sample $\mathrm{T}$ testing (see Table 4), the vales of sig in seven dimensions of kindergarten qualification examination are above 0.05 , which indicates that the difference is not obvious. Because in Zhejiang Province, the vocational schools with pre-school education major are in a small amount. Seen from data, there is no difference in identification of kindergarten teacher qualification examination system by different types of kindergarten teacher cultivation units.

Speaking from the essence, the education system is the rule to standardize and regulate people's education behavior and the relations. The basic question of the education system is people's approval of or observing education system. The education system which nobody approves, observes or most people intended to violate is an invalid education system. The results appeared to show that the new teacher qualification system is accepted by all kinds of pre-students cultivation units.

New system of teacher certification, before 2014, there have been a number of small pilot projects that have experimented with reform in the cities of Zhejiang, Shanghai and Hubei provinces in China. But the results obtained from this study can predict that the new system should be implemented nationally successfully.

4) The degree of identification of qualification recognition by different types of kindergarten teacher cultivation units is the lowest.

Seen from statistic analysis results in Table 5 (in which in this table, 1 representatives of junior collage, 2 representatives of the undergraduate), on the whole, among the four dimensions of organization form, examination objects, timeliness, examination mode, the average value of junior college is higher than that of undergrad-

Table 4. Independent samples $\mathrm{T}$ test of different types of teacher cultivation units.

\begin{tabular}{|c|c|c|c|c|c|}
\hline Identification dimensions & Educational background & M & SD & Sig & $\mathrm{t}$ \\
\hline \multirow{2}{*}{ Organization form } & 1 & 4.5 & 0.47791 & \multirow[b]{2}{*}{0.593} & \multirow[b]{2}{*}{0.262} \\
\hline & 2 & 4.4333 & 0.64884 & & \\
\hline \multirow{2}{*}{ Examination objects } & 1 & 4.3667 & 0.45677 & \multirow{2}{*}{0.454} & \multirow{2}{*}{0.593} \\
\hline & 2 & 4.2333 & 0.54546 & & \\
\hline \multirow[b]{2}{*}{ Qualification recognition } & 1 & 3.9 & 1.44914 & \multirow[b]{2}{*}{0.292} & \multirow[b]{2}{*}{0.000} \\
\hline & 2 & 3.9 & 1.10050 & & \\
\hline \multirow{2}{*}{ timeliness } & 1 & 4.4 & 0.96609 & \multirow{2}{*}{0.641} & \multirow{2}{*}{0.192} \\
\hline & 2 & 4.3 & 1.33749 & & \\
\hline \multirow[b]{2}{*}{ Examination mode } & 1 & 4.5333 & 0.54885 & \multirow[b]{2}{*}{0.144} & \multirow[b]{2}{*}{0.809} \\
\hline & 2 & 4.3 & 0.72776 & & \\
\hline \multirow{2}{*}{ Examination contents } & 1 & 4.2667 & 0.56218 & \multirow{2}{*}{1} & \multirow{2}{*}{-0.264} \\
\hline & 2 & 4.3333 & 0.56656 & & \\
\hline \multirow{2}{*}{ Assessment efficiency } & 1 & 4.15 & 0.62583 & \multirow{2}{*}{1} & \multirow{2}{*}{0.000} \\
\hline & 2 & 4.15 & 0.62583 & & \\
\hline
\end{tabular}

Note: sig $>0.05$ is not obvious; sig $<0.01$ is obvious; sig $<0.001$ is obvious. 
Table 5. Description about identification by different types of teacher cultivation units.

\begin{tabular}{cccc}
\hline Identification dimensions & Educational background & M & 0.47791 \\
\hline Organization form & 1 & 4.5 & 0.64884 \\
Examination objects & 2 & 4.4333 & 0.45677 \\
& 1 & 4.3667 & 0.54546 \\
Qualification recognition & 2 & 4.2333 & 1.44914 \\
& 1 & 3.9 & 1.10050 \\
Qualification timeliness & 2 & 3.9 & 0.96609 \\
Examination mode & 1 & 4.4 & 1.33749 \\
& 2 & 4.3 & 0.54885 \\
Examination contents & 1 & 4.5333 & 0.72776 \\
Assessment efficiency & 2 & 4.3 & 0.56218 \\
& 1 & 4.2667 & 0.56656 \\
\hline
\end{tabular}

Note: in educational background, 1 represents junior college, 2 represents undergraduate.

duate and the standard deviation of junior college is less than that of undergraduate. It is concluded from the four dimensions that the degree of identification by junior college cultivation unit is higher than that of undergraduate cultivation unit, and the degree of identification by junior college cultivation unit is more stable.

In the dimension of examination contents, the average value of undergraduate is more than that of junior college, but in aspect of standard deviation, the standard deviation of undergraduate is more than that of junior college, which indicates that in this dimension, the degree of identification by undergraduate is higher than that of junior college cultivation unit.

In two dimensions of qualification recognition and qualification efficiency, the average vales of junior college cultivation units and undergraduate cultivation units are the same, which indicates that the degree of identification of qualification recognition and value by different types of cultivation units are the same. In the dimension of assessment efficiency, the average value and standard deviation of junior college and undergraduate cultivation units are the same, which indicates that in this dimension, the degree of identification and state by different types of cultivation units tend to be same. In the dimension of qualification recognition, the standard deviation of junior college is more than that of undergraduate, which indicates that in this dimension, the identification state of junior college cultivation unit is more disperse and unstable than that of undergraduate cultivation unit.

The average value of this dimension is the lowest among all dimensions which indicates that comparably, the degree of identification of administrative department for education as the only institution for kindergarten teacher qualification recognition by different types of cultivation units is low. In China, the Chinese government is the sole agency shall issue a certificate of qualification of teacher. It means the government invariably responsible for carrying a dual role, both hunter and the hunted, Both coaches and athletes. This is a very unreasonable phenomenon, no wonder no wonder it got a low indentified score.

\section{Recommendations}

The study proves the new system of qualifications for teachers in China has well-received. So it may be carried out according to the teacher qualification test and regular registration system reform to expand the pilot (teachers notice letter [2013] 2) of China. But the study suggests doing this work well, government of China must make efforts to improve the professional status and dignity of kindergarten teachers, standardize the quality level of the institution for training kindergarten teachers, extend kindergarten teacher qualification recognition in- 
stitutions, and perfect monitoring mechanism, and regulate examination contents.

\subsection{The New System of Qualifications for Teachers May Be Carried out According to Plan}

Getting the backing of the institution for training kindergarten teacher, who is one of the main stakeholders of teacher certification system, is very important for China government to implement new teacher certification system.

Since 2011, teachers' qualification examination has carried out nationwide examination pilot reform in Hubei, Shanghai, Guangxi, Hainan, Hebei, Shandong, Anhui, Shanxi, Guizhou, and Zhejiang province. According to the Chinese Ministry of education plans, the new system will promote in the country before 2015. The results of this study show The Chinese government's plan can be carried out smoothly. But the Chinese government still has to address several issues, such as professional status and dignity of kindergarten teacher, the quality level of the institution for training kindergarten teachers, the certification bodies of kindergarten teacher, and the form and content of the examination.

\subsection{Make Efforts to Improve the Professional Status and Dignity of Kindergarten Teachers}

A kindergarten teacher qualification standard is the core content of kindergarten teacher qualification system [2]. We can see from the investigation results that, a great number of Zhejiang's training institutions have high degree acceptance of the certificate system of kindergarten teachers. However, they also show lower degree of acceptance of kindergarten teacher's professionalization and the security effect of the certificate system of kindergarten teacher on kindergarten teachers' professionalization.

To some extent, kindergarten teacher's professionalization indicates he continuous development of nursery education, the constant scientization of the social recognition toward nursery education and the unceasing development of social civilization. Nevertheless, kindergarten teacher's professionalization, never simply referring to professional academic study and academic degree, is also reflected in teacher's personal characteristics, professional practice and social work. Development of professionalization doesn't simply equal to promotion of academic degree. In fact, it is a broad cultivation and practice, including self-cultivation.

In the book the Base of Early Education, George Morrison proposed four dimensionalities to review kindergarten teacher's professionalism: 1) Individuality, including personality, emotional quality, physical and mental health, etc.; 2) Level and background of education, including course learning of associate degree, bachelor degree, master degree, study for national vocational qualifications related to child development and study of preparation course related to child development, etc.; 3) Professional practice, including the understanding of children, development of and culture suitability practice, determination of educational practical idea, cooperation with family members (e.g., parents) and community partners, participation in moral practice; 4) Public work: e.g., publicity, public-oriented professional speech, professional presentation for the public, etc. [3].

In the current Chinese society, at the doctrinal level, kindergarten teacher's professionalization is imperative. However, at the level of public awareness, the professionalism of kindergarten teachers has not been fully determined. A lot of people, or even some training institutions, haven't realized the necessity of kindergarten teacher's professionalism in a satisfactory way. In such a historic context, the Chinese government must strengthen relevant publicity and education. It's necessary for them to comprehensively improve social public's recognition and acceptance of kindergarten teacher's professionalization, and make sure the teachers' professionalism can be guaranteed and confirmed in levels of status, treatment, dignity and obligation. Only in this way can a high-quality team of kindergarten teacher can be established.

\subsection{Standardize the Quality Level of the Institution for Training Kindergarten Teachers}

At present, many Chinese kindergarten-teacher training institutions are still using the conventional cultivation modes of curriculum provision and student cultivation, which can no longer satisfy the needs of training high-level kindergarten teachers. Meanwhile, according to the announcement of the Chinese government, it's necessary to "adjust the level and layout of normal schools, encourage comprehensive universities and nonnormal colleges to participate in the training and cultivating of primary and secondary school teachers, and explore the way of pilot operation of normal schools in qualified comprehensive universities and colleges” [4]. 
Since normal education for kindergartens has promising "career prospects", it becomes one hot major raced to set up by various schools, especially vocational technical institutes. However, neither the curriculum provision nor teacher quality of these schools and institutes are dependable. The education operation ability of most of these schools is poor, therefore their graduates' quality can be hardly guaranteed.

As a result, on the one hand, the Chinese government must issue some policies to restrain the status of widespread kindergarten-teacher training institutions; on the other hand, it's necessary to supervise and guide the training institutions, so that the early education science can be integrated with the teacher education curriculum system. In this way, more accurate professional ideas, knowledge and skills can be mastered by kindergarten teachers to promote their quality specificity and irreplaceability and improve their working abilities and levels.

\subsection{Extend Kindergarten Teacher Qualification Recognition Institutions}

The observing of system is influenced by three factors, which refer to power constraint, consciousness control, and public identification [4]. As the improving of technology and public quality, the social relation becomes more and more symmetric. The legitimacy of power should first be proved as well as the impossibility of consciousness control in technology, with their effective space contracted. In contemporary society, only the system with manifestation of public rational spirit can realize self-conscious observation. At present, the formulation and execution of Chinese kindergarten teacher qualification are undertaken by administrative department for education. Concluded from the famous statement from Kant that power ideology and rational power are symbiotic, the formulation right of system must belong to all social members - for that any organization or individual can not understand interest appeal of all social members. It is found in the result of survey that the grades of identification of principle unit of teacher qualification recognition [5] by objects are the lowest (which refers to the average value of the dimension of qualification recognition which is the lowest). The result appeals to that Chinese government should break off the situation where administrative department for education plays roles in both coach and judge according to practical situation in China and explore actively the paths for extending diversion of qualification recognition institutions.

\subsection{Perfect Monitoring Mechanism, and Regulate Examination Contents}

Combining with different results of identification degree of kindergarten teacher qualification examination contents by different types of cultivation units, we think that the supervision mechanism of kindergarten teacher qualification should be reinforced for ensuring the fairness and justice of examination, because the formulation and execution of system are the materialization of public rights. If those behaviors and criteria involve other rights which are in contradiction to public interest, they are not just [6]. When the system design involves the realization of profits of social members, the hindering of channels for process of system formulation and system execution is unjust. As a result, the supervision system should be established in the procedures of formulation and execution of Chinese teacher qualification system to evaluate all levels and all types of teacher qualification from the standpoint of third party, including the examination contents and rationality of kindergarten teacher qualification.

\section{References}

[1] Zhou, H.Y. (2013) The Top Design of Teacher Education System Some Thinking and Suggestions. Teacher education forum, 6, 4-17.

[2] Sun, A.Q. and Feng, X.X. (2008) Problems and Thinking on Examination of Kindergarten Teacher's Qualification in China. Studies in Preschool Education, 6, 8-10.

[3] Morrison, G.S. (2003) Fundamentals of Early Childhood Education. 3th Edition, Merrill Prentice HALL, 276-305.

[4] The CPC Central Committee and the State Council (1999) Deepening Education Reform and Promoting Quality Education Decision. 1999-06-13.

[5] Wang, J.F. (2009) On Identification of System. Lanzhou Academic Journal, 23, 28-33.

[6] Kant (2005) Discussion on Problem of Enlightenment. In: Collected Works of Historical Rational Criticism. Commercial Press, Beijing, 23-32, 158. (Translated by He Zhaowu) 
Scientific Research Publishing (SCIRP) is one of the largest Open Access journal publishers. It is currently publishing more than 200 open access, online, peer-reviewed journals covering a wide range of academic disciplines. SCIRP serves the worldwide academic communities and contributes to the progress and application of science with its publication.

Other selected journals from SCIRP are listed as below. Submit your manuscript to us via either submit@scirp.org or Online Submission Portal.
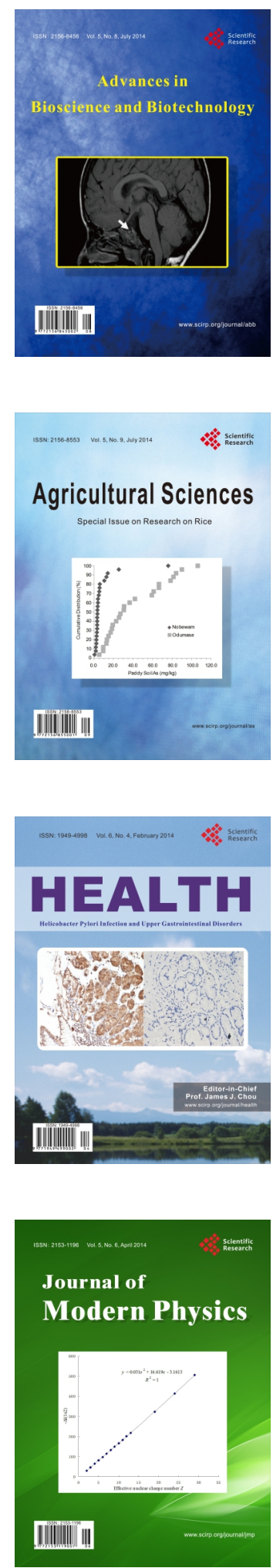
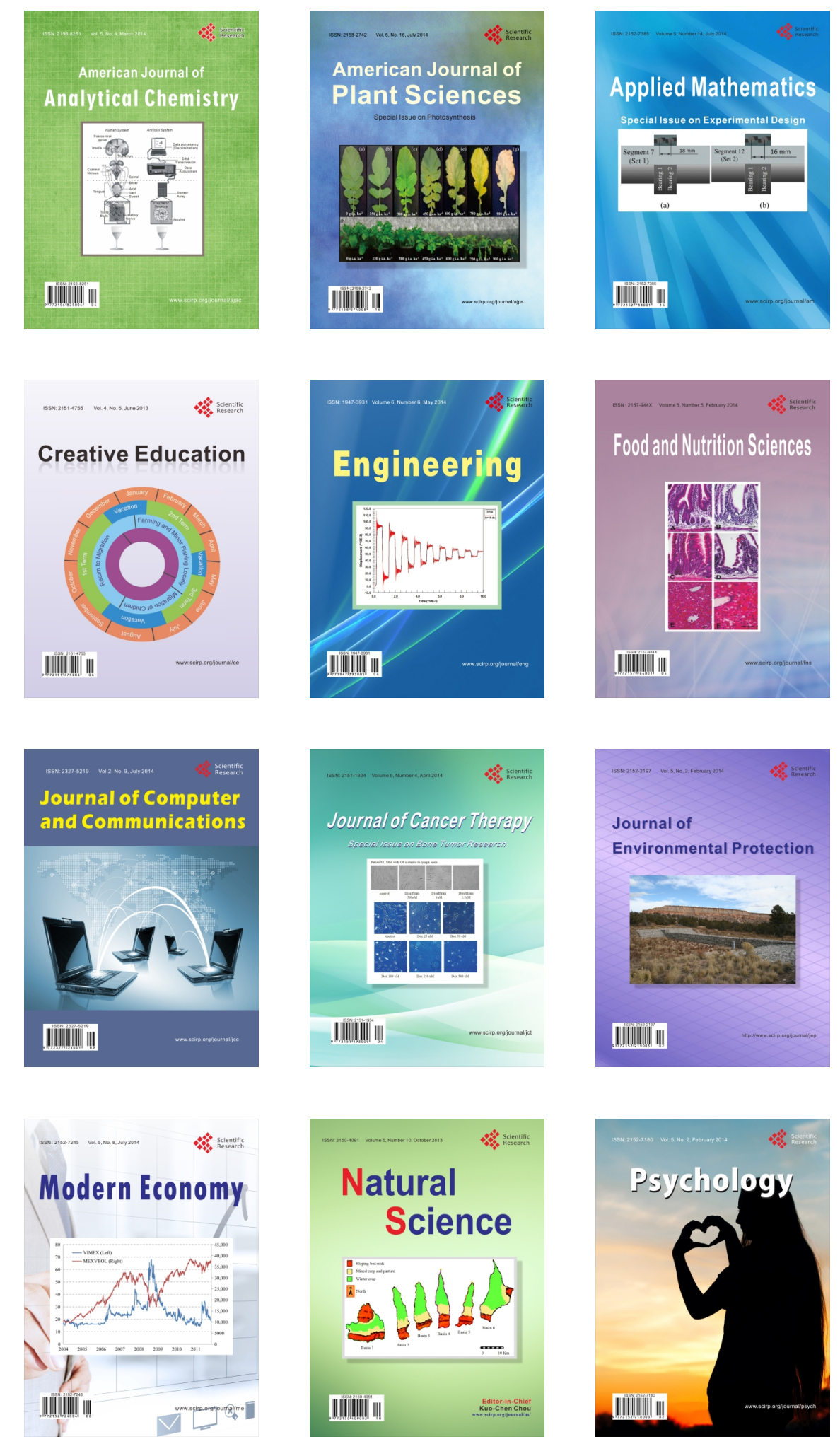